\title{
Relation of socio-economic status to the independent application of self-care in older persons of South Africa
}

\author{
Tinda Rabie*, Hester C. Klopper, Martha J. Watson \\ INSINQ Focus Area, Faculty of Health Sciences, North-West University, Potchefstroom Campus, South Africa
}

\section{A R T I C L E I N F O}

Article history:

Received 20 February 2015

Accepted 26 February 2015

Available online 1 October 2015

Keywords:

Older person

Self-care

Socio-economic status

\begin{abstract}
A B S T R A C T
Background: Many older persons in South Africa (SA) are affected by a poor socio-economic status, leading to an increase in the use of the public healthcare sector. However, the public healthcare sector is burdened by high volumes of patients and long waiting periods. As a result, professional nurses in primary healthcare ( $\mathrm{PHC}$ ) facilities are not able to spend enough time on proper physical examinations and assessment of needs, including health education and support to older persons to help them apply independent self-care.

Aim: To determine if the socio-economic status of older persons affects their ability to apply self-care independently without support from professional nurses in the PHC facility. Design: Quantitative, descriptive research design.

Methods: Older persons ( $\mathrm{N}=198 ; \mathrm{n}=192$ respondents) were asked to complete the Appraisal of Self-care Agency (ASA-A) and Exercise of Self-care Agency (ESCA) questionnaires. Seven self-care deficits were identified through deductive logic after analysis of the two questionnaires. These seven self-care deficits were compared to the socio economic status of the same sample.

Results: Seven self-care deficits were identified after analysis of the ASA-A and ESCA questionnaires. One self-care deficit was found to have a relationship with the socioeconomic status of the older persons.

Conclusions: Low literacy levels of older persons with a low socio-economic status affect their ability to apply self-care independently without the support from a professional nurse in the PHC facility. Data analysis of the ASA-A and ESCA revealed that these older persons suffer from a "lack of knowledge and ability to acquire knowledge with regard to self-care" which had a relationship with the socio-economic status of older persons with specific reference to low literacy levels and poverty.

Implications for practice: More attention should be given to older persons with a low socioeconomic status as their ability to apply self-care independently without the support from a professional nurse is limited. This would lead to less frequent visits to PHC facilities by older persons for minor ailments, decrease healthcare costs, relieve overcrowding in PHC facilities and prevent possible unintentional self-neglect.
\end{abstract}

@ 2015 The Authors. Publishing services by Elsevier B.V. on behalf of Johannesburg University. This is an open access article under the CC BY-NC-ND license (http:// creativecommons.org/licenses/by-nc-nd/4.0/).

\footnotetext{
* Corresponding author. North-West University, School of Nursing Science, South Africa. Tel.: +27 182991719.

E-mail addresses: tinda_rabie@yahoo.com (T. Rabie), klopperhc@gmail.com (H.C. Klopper), Mada.Watson@nwu.ac.za (M.J. Watson). Peer review under responsibility of Johannesburg University. 


\section{Introduction}

Currently, ageing of the global population represents one of the most distinctive changes in the demographic profile. In parts of the population where there are scarce resources, ageing has the potential to become a major issue, especially as it has been predicted that the population of old people is going to increase in the next two to three decades. Worldwide there are 600 million people over the age of 60 years (World Health Organization, 2013). The United Nation's estimated projection of older persons in 2000 was 21.3 million, with the figure expected to rise to 80.3 million in 2025. Sub-Saharan Africa has a lower number of older persons compared to other developing regions (Kimuna, 2005, p. 13). According to Nabalamba and Chikoko (2011, p. 2), the older population in Africa accounts for $3.6 \%$ of the entire population and this percentage is expected to rise to $4.5 \%$ in 2030 and to $10 \%$ in 2050. In South Africa in 2001 there were 3.3 million persons over 60 years of age (Turok, 2006, p. 1), which represented $7.5 \%$ of the total population; this number has since increased to $7.7 \%$ (Statistics SA, 2011). In the North West (NW) province the 2011 census revealed that the percentage of older persons $(60+$ years of age) increased to $7.7 \%$ (Statistics SA, 2011) from 7.34\% in 2001 (Joubert \& Bradshaw, 2004, p. 152). The reality of the increasing older population is putting increased pressure on the public healthcare sector serving $83 \%$ of the total South African population (Council of Medical Schemes, 2011). This means that professional nurses are not able to spend enough time on physical examinations and health education focusing on independent application of self-care in the PHC facilities.

Additionally, older persons have different socio-economic needs that should be considered; for example accessibility of healthcare, needs regarding nutrition, shelter, clothing, transportation, community amenities and various types of abuses (May, 2003). Previous health experiences, the nature of medical complaints, past experiences at healthcare services, requests for information and advisory visits to healthcare facilities are all issues that are faced by older persons (Laditka, 2004, p. 233;Vožehová, Zikmundová, Zavázalová, Zaremba, \& Vlasák, 2003, p. 48) together with the reality of a low socioeconomic status (Nabalamba \& Chikoko, 2011, p. 12). The studied population is also affected by a low-socio-economic status, low literacy levels and poverty. Due to the latter, they have no other choice than to visit PHC facilities which is the first point of access to healthcare for patients in the public healthcare sector.

PHC was introduced in South Africa in 1994 to reform the health services. The focus of PHC is to make essential services freely available, cost-effective, affordable and equal to all members of the population, and includes the care and treatment of chronic and other diseases in older persons (Hattingh, Dreyer, \& Roos, 2010, p. 65; Phaswana-Mfuya et al., 2008, pp. 611-612). According to Hattingh, Dreyer, and Roos (2012, p. 70), PHC stresses self-reliance and self-determination and therefore aims to redistribute power and build self-confidence in people. This also applies to older persons and should be able to assist them to increase their independence in caring for self. Self-care among older persons has the potential to reduce medical care needs as well as healthcare costs (Joubert
\& Bradshaw, 2004, p. 157; Lloyd-Sherlock, 2004, pp. 292-294; SA, 2004, p. 3).

However, according to The DG Murray Trust (2012:4), the healthcare provided to older persons in the public sector is not satisfactory. This could be due to a lack of expertise in the care of older people, leading to a systematic failure of the system. Other factors in the public healthcare sector which possibly also affect the older person to independently apply self-care include ineffective appointment arrangements, lack of medication, poor handling of physical examinations (Turok, 2009, p. 1), overcrowding, long waiting periods, staff shortages, inadequate provision of health education to specifically older persons, poor quality of care and disrespect (Kruger, Greeff, Watson, \& Fourie, 2009, p. 42). This uncaring attitude is not intentionally inflicted on older persons in the PHC facilities, but is rather as a result of factors such as time constraints, staff shortages, high workloads and overcrowded public PHC facilities which lead to frustration among the staff (Bradshaw \& Steyn, 2001, p. 9; Turok, 2006 , p. 5). More attention should thus be given to the management of older persons' health problems and their independent self-care abilities in PHC facilities.

If older people do not have sufficient knowledge about their healthcare problems, including their chronic diseases, they will not know how to independently treat or take care of themselves, and the less they know, the less they will discuss any issues they have with the healthcare provider, thereby decreasing their self-care ability (Guinn, 2004, p. 270; Bastiaens, Van Royen, Rotar Pavlic, Raposo, \& Baker, 2007, p. 38).

Gibbons (2006, p. 324) mentions that self-care means purposeful management of the self and could be considered intentional. Other authors such as Kendall and Rogers (2007, p. 130) and Lauder (2001, p. 96) describe self-care as activities a person engages in to promote health, prevent disease, assess symptoms and reinstate optimal healthy functioning. Selfcare also includes those actions a person engages in to ensure optimal health for a long period of time or to preserve health and ensure healthy functioning by taking part in selfdevelopment activities in order to prevent self-neglect (Tomey, \& Alligood, 2006, p. 269).

Self-care encompasses the following concepts: self-care agency, self-care agent and self-care deficit (Orem, 2001, pp. 53; $268 \& 282$ ). Self-care agency refers to the ability (capability and power) a person has to engage in self-care operations (Callaghan, 2006, p. 45; Evers, Isenberg, Philipsen, Senten, \& Brouns, 1993, p. 332; Lauder, 2001, p. 96; Orem, 2001, p. 53; Tomey \& Alligood, 2006, p. 271). Self-care agent refers to the individual who engages in self-care (Orem, 2001, p. 268; Tomey \& Alligood, 2006, p. 271), and self-care deficit refers to the limitations in the self-care ability and power of the selfcare agent to meet therapeutic self-care demands (Orem, 2001, p. 282). Lastly, self-neglect means that a person is not able to provide goods or services to self to meet basic needs (Deyer, Goodwin, Pickens-Pace, Burnett, \& Kelly, 2007, p. 1671).

The initial healthcare profile obtained during the Prospective Urban and Rural Epidemiological study (PURE) (Kruger, 2005 , p. 4) revealed that the studied older population had a low socio-economic status and was affected by low literacy levels and poverty (Watson, 2008, pp. 72-74) (see Table 1). The 
literature mentions the following factors that affect the older populations' ability to independently apply self-care, which may lead to self-neglect.

- Many older persons affected by poor health and chronic diseases stay in their own residences and not in old-age homes. This is because they cannot afford to stay in oldage homes, where professional nurses can support them in the independent application of self-care to manage their diseases.

- Older persons are not a priority in South African healthcare (Ntusi \& Ferreira, 2004, p. 3).

- Most older persons do not have any general knowledge about their health conditions and how to handle these conditions (Deyer et al., 2007, p. 1672).

- The majority of older persons (55\%) in the studied population mentioned above have no or only primary education. This excludes them from searching, finding and reading information about self-care (see Table 1).

- Most of the older persons cannot afford a private medical fund and form part of the $83 \%$ of the general population who must visit PHC facilities in the public healthcare sector (Council of Medical Schemes, 2011), which is burdened by overcrowding, long waiting times, staff shortages and poor quality of care (Kruger et al., 2009, pp. 42 \& 43).

- Poverty contributes to a lack of healthcare seeking behaviour (Kruger et al., 2009, p. 42), especially in view of the travelling costs and physical challenges involved in attending a PHC facility.

\section{Method}

The research method involved participants, sampling, data collection, data analysis, reliability and validity.

\subsection{Participants and sampling}

This study made use of a quantitative, descriptive research design and was embedded in the larger PURE-SA study (Kruger, 2005). The participants were made up of a proportion of the older persons who participated in the PURE-SA study and lived in their private residences in a semi-urban district of Potchefstroom, in the North West in South Africa. A total number of 198 questionnaires were disseminated to the participants for completion, and 192 were returned resulting in a 98\% response rate. The healthcare profile data was obtained as part of the initial data collection of the PURE-SA study on the same older population. The healthcare profile included the bio-physical, psychological well-being, and socio-economic factors, lifestyle behaviour and support system (Table 1) (Watson, 2008, pp. 72-74). For the purpose of this study the researchers only used the data focusing on the socioeconomic factors of the studied population.

\subsection{Data collection}

Data was collected in two phases.

\subsubsection{Phase 1}

The healthcare profile of the older population was obtained during the initial PURE data collection process. As mentioned previously, the healthcare profile included information on the biophysical, psychological well-being and socio-economic factors, lifestyle behaviour and support system. For the purpose of this article the researchers only focused on the socio-economic factors which included the educational profile, main source of income, number of persons living in the houses of the older persons being studied, household conditions and social support.

\subsubsection{Phase 2}

The researchers employed two structured questionnaires, the ASA-A developed in 1988 by Evers et al. (1993) and the ESCA developed by Kearny and Fleischer (1979), based on Dorothea Orem's self-care deficit theory of nursing which focuses on measuring the self-care ability of a person. Before the questionnaires were used, permission was asked and obtained from the developers of both the ASA-A and ESCA. The researchers, with the assistance of Setswana-speaking fieldworkers, firstly conducted a pilot study to identify any problems that could be encountered during data collection.

After the pilot study the researchers made some minor adapatations, which included translation of the questionnaires into Setswana and changing the original 5-point Likert scale to a 3-point Likert scale to fit the older Setswanaspeaking population. This was done because the studied population was Setswana speaking and $29 \%$ had no education and $55 \%$ had only a primary education (see Table 1 ). The fieldworkers mentioned after the pilot study that they themselves and the participants would understand the questionnaires better in their mother tongue which was Setswana.

Before the fieldworkers started with the data collection, each of the participants was provided with a letter that provided background information on the study and explained the purpose of the study. The letter also provided the ethical approval number and voluntary consent from. The fieldworkers then verbally explained the abovementioned information and therafter obtained consent before starting with the data collection. The fieldworkers, mainly Setswana speaking, completed the questionnaires on behalf of the older persons who where not literate by verbally asking the questions on both questionnaires and recording the answer on the questionnaire as provided by the older person.

\subsection{Data analysis}

Data analysis was conducted in two phases.

\subsubsection{Phase 1}

The healthcare profile was analysed during inital data collection by Watson (2008, pp. 72-74). Descriptive statistics were obtained after analysis of the healthcare profile (which included the socio-economic status) of the older persons by using SPSS 15.1 for Windows (1989-2008) (see Table 1).

\subsubsection{Phase 2}

The self-care ability (capability and power) of the older person was examined by using descriptive statistics. Descriptive 
statistics assessed the variable distribution which provided the opportunity to arrange the data in such a manner that it could be understood, and to give meaning to the phenomenon of self-care from various angles (Burns \& Grove, 2005, p. 375; Maree et al., 2012, p. 19).

\subsection{Reliability and validity}

The fieldworkers who assisted in data collection of the ASA$A$ and ESCA were part of the initial PURE-SA study and therefore knew the studied population. The fieldworkers also received training prior to the data collection on completion of the questionnaires and on each and every question asked. The questionnaires had a high Cronbach's alpha coefficient after analysis - Cronbach's alpha coefficient of the ASA-A was .79 and for the ESCA it was .89 , indicating a high reliability.

\section{Ethical considerations}

The study was approved by the NWU ethics committee and formed part of the PURE-SA study that focuses on older persons (ethical approval Number 04M10). The participants of the study were mainly Setswana speaking and had low literacy levels. The researchers thus used Setswana-literate fieldworkers for data collection so that they could explain the background information and the purpose of the study to the participants in their mother tongue, i.e. Setswana. The participants were also informed that participation was voluntary and that they could withdraw at any time with no penalty against them. They were also assured of confidentiality. Before the data collection commenced, all participants gave voluntary consent by signing (or marking) a consent form. Throughout the study care was taken to maintain confidentially and anonymity of all the information.

\section{Results}

The results of this study were obtained in two phases, which included both the results of the socio-economic status which formed part of the initial healthcare profile obtained by Watson (2008, pp. 72-72) of the studied older population and the self-care deficits deducted from the ASA-A and ESCA questionnaires.

\subsection{Phase 1}

\subsubsection{Socio economic status}

South Africa is burdened with severe inequality and poverty (Kinkel, Marcus, Memon, Bam, \& Hugo, 2013, p. 2). The socioeconomic profile of the studied older persons supports this statement as it indicated that the older persons had a poor educational profile, with $29 \%$ having no education, $55 \%$ having primary education and only $10 \%$ of the population having a secondary education (see Table 1). According to Statistics SA (2012, p. 116), 38\% of the total black older population of SA has no primary education, which means that older persons living in the North West showed a slightly higher literacy level than the average older person in South Africa (see Table 1). Older persons in South Africa are reliant on a grant (older persons grant) each month (Statistics SA, 2012, p. 116). This was also true for the studied population. It was found that $72 \%$ received an older persons grant, $7 \%$ were employed, 5\% received money from their family and $8 \%$ had no income (see Table 1). The percentage of $72 \%$ of older persons receiving an older persons grant is in line with 69\% (in 2011) of the South African population receiving an older persons grant each month (Statistics SA, 2012, p. 116). In the houses of the older persons, 95\% had orphans or other persons living with them (see Table 1). This percentage correlates very well with the greater South African population as according to Statistics SA (2012, p. 115), the child dependence ratio in households where

Table 1 - Socio-economic profile of the studied population $(\mathbf{N}=198)$.

\begin{tabular}{llll}
\hline Educational profile & None: & $\mathrm{n}=57$ & $29 \%$ \\
& Primary: & $\mathrm{n}=108$ & $55 \%$ \\
& Secondary: & $\mathrm{n}=20$ & $10 \%$ \\
& Missing: & $\mathrm{n}=13$ & $6 \%$ \\
Main source of income & Pension: & $\mathrm{n}=142$ & $72 \%$ \\
& Employed by themselves/other & $\mathrm{n} 14$ & $7 \%$ \\
& person/other organisation: & & $5 \%$ \\
& Family: & $\mathrm{n}=9$ & $8 \%$ \\
& No income: & $\mathrm{n}=18$ & $8 \%$ \\
Missing: & $\mathrm{n}=15$ & $22 \%$ \\
Number of people living in & $\geq 6$ & $\mathrm{n}=44$ & $73 \%(5 \%$ missing) \\
houses of older persons & $\leq 6$ & $\mathrm{n}=145$ & $98 \%(8 \%=$ No; $4 \%$ missing) \\
Household conditions & Electricity: & $\mathrm{n}=174$ & $72 \%(23 \%$ community well/bore hole; \\
& Roof: & $\mathrm{n}=183$ & $1 \%$ fetch from river/dam; $4 \%$ missing) \\
& Water supply: (Piped) & $\mathrm{n}=142$ & $22 \%$ \\
Social support & & & $3.5 \%$ \\
& Family: & $\mathrm{n}=44$ & $4.5 \%$ \\
& Children: & $\mathrm{n}=7$ & $0 \%$ \\
& Community: & $\mathrm{n}=9$ & $70 \%$ \\
\hline
\end{tabular}


older persons stayed was an average of 1.24 . In $22 \%$ of the households there were more than six persons living in the household and in $73 \%$ there were less.

Overall, the conditions of the respective households were relatively acceptable as the following percentages were reported: $88 \%$ had electricity and $72 \%$ had piped water supply (see Table 1). These statistics reflects the finding of Statistics SA (2012, p. 117) which found that since 2002 older persons were more likely to have access to resources such as piped water, flush toilets and electricity. From Table 1 it can be seen that $22 \%$ of the older persons' family supported them, $3.5 \%$ children supported them, $4.5 \%$ had support from the community, and $70 \%$ had other forms of support. The latter is also true of the general SA population where, according to Statistics SA (2012, p. 115), older persons not only provide, but also depend on social support networks.

\subsection{Phase 2}

\subsubsection{Self-care deficits}

Analysis of both the completed ASA-A and ESCA questionnaires enabled the researchers to deduct seven self-care deficits based on Dorothea Orem's self-care theory of nursing (see Table 2). The following self-care deficits were found in older persons: deficit in time management skills; an energy deficit; sleep deprivation; a lack of knowledge and ability to acquire knowledge with regard to health and selfcare; a lack of rest, exercise and self-care programme; a deficit caused by physical deterioration; and lastly, they experience a lack in the performance of activities to prevent/ decrease self-care deficits. population, namely "lack of knowledge and ability to acquire knowledge with regard to health and self-care". This could be due to the low socio-economic status which more specifically includes low literacy levels and poverty. These factors and factors such as time constraints, staff shortages, high workloads and overcrowding in PHC facilities affect the older persons' ability to independently apply self-care. .

However, PHC focuses on giving back the power to the patient, including the older person with low socio-economic status, so that they can become more independent and selfreliant to apply self-care. It is therefore vital that PHC facilities provide additional support on the independent application of self-care to ensure optimal health for the older persons, in particular those with a lower socio-economic status who are more likely to be lacking in knowledge and who thus need to acquire knowledge with regard to health and self-care.

\section{Recommendations for further research}

The following research recommendations are suggested to assist older persons affected by low socio-economic status in the independent application of self-care:

- The perceptions of professional nurses should be explored with regard to the implementation of measures to assist older persons in the independent application of self-care.

- The perceptions of clinic staff and older persons should be examined with regard to the importance of the application on self-care.

\section{Table 2 - Self-care deficits identified in the ASA-A and ESCA $(\mathbf{N}=198)$.}

Self-care deficits

The older person has a deficit in time management skills, affecting self-care.

The older person has an energy deficit, affecting self-care.

The older person has a sleep deprivation deficit.

The older person has a lack of knowledge and ability to acquire knowledge with regard to health and self-care.

The older person has lack of a rest, exercise and self-care programme.

The older person has a self-care deficit caused by physical deterioration.

The older person experiences a lack in the performance of activities to prevent/decrease self-care deficits.
Items of the ASA-A and ESCA indicating the self-care deficits after analysis of descriptive statistics

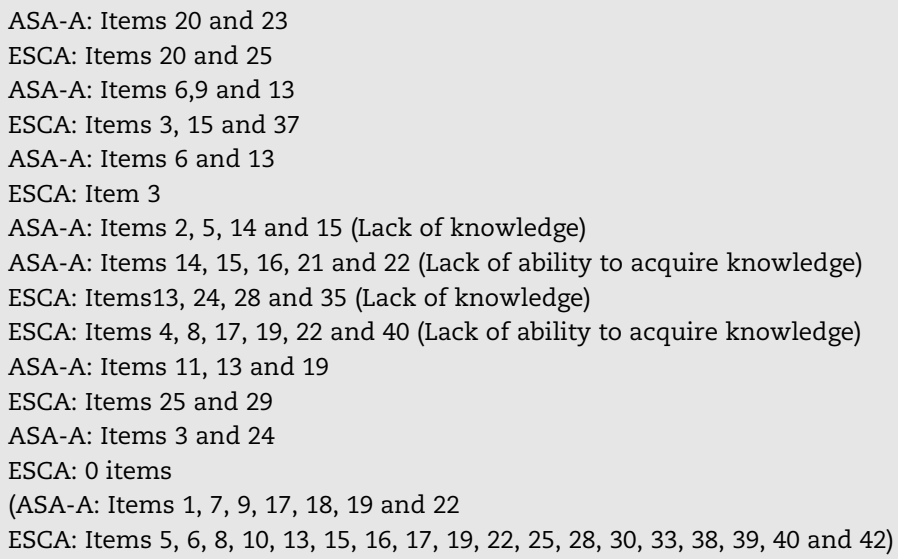

\section{Discussion}

From the identified self-care deficits (see Table 2) only one had a relationship with the socio-economic status of the studied
- Research needs to be conducted on the feasibility of the regular implementation of well-planned self-care health education sessions for older persons in order to assist them in the independent application of self-care.

- The level of commitment of older persons to apply selfcare needs to be explored in more depth. 
- Research on the self-care ability of older persons in South Africa in different cultures and in different socio-economic situations should be done.

\section{Limitations of this study}

The PURE-SA study did not include all the older persons in the peri-urban district of Potchefstroom, and therefore the results could only be used as a general guide for other older populations. The participants of this study were predominantly of the Setswana ethnic group and thus the results may not be representative of other ethnic groups and can only be used as a general guideline.

\section{Implications for practice}

PHC facilities supporting older persons to independently apply self-care could decrease unnecessary healthcare costs caused by older persons who lack the self-care knowledge required to manage minor health problems. Such facilities would assist in improving the quality of life of older persons, healthcare costs would drop and overcrowding at PHC facilities would be alleviated because minor ailments would have been independently handled by the older person. The older person would also be saved from unnecessarily attending a PHC facility where they are confronted with overcrowding and long waiting periods to manage a minor health problem they could have managed by themselves.

\section{Conclusion}

Older persons in the studied population had a low socioeconomic status and were especially affected by low literacy levels and poverty. Data analysis of the ASA-A and ESCA to determine the ability of older persons to apply self-care revealed that there was a lack of knowledge and an inability to acquire knowledge by themselves with regard to self-care. The older population thus needs support from professional nurses in PHC facilities to help them apply self-care independently. By giving this support to older persons, the PHC service model in the public healthcare sector can play a vital role as it aims to promote self-reliance and independence by giving people back their power and self-confidence. This approach would also assist in reducing medical needs, healthcare costs, overcrowding and long waiting periods.

\section{Authors' contributions}

Dr T. Rabie was a postgraduate student and Prof. H.C. Klopper and Dr. M.J. Watson were the promoters who assisted Dr. T. Rabie in the development of this article.

\section{Acknowledgements}

The authors would like to thank all supporting staff and the participants of the PURE-South Africa study and in particular the following:
1. The PURE-SA research team, and in particular Prof Annamarie Kruger, the principal investigator and coordinator of the South African leg of PURE; Dr Mada Watson who was responsible for the gerontology data used in this study, field workers and office staff in the Africa Unit for Transdisciplinary Health Research (AUTHeR), Faculty of Health Sciences, North-West University, Potchefstroom, South Africa.

2. Funders of the PURE-SA study: SANPAD (South Africa-Netherlands Research Programme on Alternatives in Development), South African National Research Foundation (NRF GUN numbers 2069139 and FA2006040700010), NorthWest University, the Population Health Research Institute in Ontario Canada and the Medical Research Council of SA.

\section{R E F E R E N C E S}

Bastiaens, H., Van Royen, P., Rotar Pavlic, D., Raposo, V., \& Baker, R. (2007). Older people's preferences for involvement in their own care: a qualitative study in primary health care in 11 European countries. Patient Education and Counselling, 68, 33-42.

Bradshaw, D., \& Steyn, K. (2001). Poverty and chronic diseases in South Africa. Technical report. Retrieved from http://www.mrc. ac.za/bod/povertyfinal.pdf.

Burns, N., \& Grove, S. N. (2005). The practice of nursing research conduct: Critique and utilization (5th ed.). St. Louis, MO: Elsevier.

Callaghan, D. (2006). The influence of growth on spiritual self-care agency in an older adult population. Journal of Gerontological Nursing, 32(9), 43-51.

Council for Medical Schemes. (2011). Annual report 2010/11. Pretoria, SA: Council for Medical Schemes.

Deyer, C. B., Goodwin, J. S., Pickens-Pace, S., Burnett, J., \& Kelly, P. A. (2007). Self-neglect among the elderly: a model based on more than 500 patients seen by a geriatric medicine team. American Journal of Public Health, 97(9), 1671-1676.

Evers, G. C. C., Isenberg, M. A., Philipsen, H., Senten, M., \& Brouns, G. (1993). Validity testing of Dutch translation of the appraisal of self-care agency A.S.A.-Scale. International Journal for Nursing Studies, 30(4), 331-342.

Gibbons, S. (2006). Primary care assessment of older adults with self-care challenges. The Journal for Nurse Practitioners, 2(5), 323-328.

Guinn, M. J. (2004). A daughter's journey promoting geriatric selfcare: promoting positive health care interactions. Geriatric Nursing, 25(5), 267-271.

Hattingh, S., Dreyer, M., \& Roos, S. (2010). Aspects of community health (3rd ed.). Cape Town, SA: Oxford University Press.

Hattingh, S., Dreyer, M., \& Roos, S. (2012). Community nursing a South African manual (4th ed.). Cape Town, SA: Oxford University Press.

Joubert, J., \& Bradshaw, D. (2004). Health of older persons. South African Medical Research Council. Retrieved from http://www. mrc.ac.za/bod/outputs2004.pdf.

Kearny, B. Y., \& Fleischer, B. J. (1979). Development of an instrument to measure exercise of self-care agencies. Research in Nursing Health, 2(1), 25-34.

Kendall, E., \& Rogers, A. (2007). Extinguishing the social state sponsored self-care policy and the chronic disease selfmanagement programme. Disability and Society, 22(2), 129-143.

Kimuna, S. R. (2005). Socio-economic support of older people in Zimbabwe. Bold, 15(4), 13-27.

Kinkel, H., Marcus, T., Memon, S., Bam, N., \& Hugo, J. (2013). Community oriented primary care in Tswane district, South 
Africa: assessing the first phase of implementation. African Journal of Primary Health Care Family Medicine, 5(1), 1-9.

Kruger, A. (2005). Prospective urban and rural epidemiological study (PURE): Instruction manual for South Africa (2nd draft). Potchefstroom: North-West University.

Kruger, A., Greeff, M., Watson, M. J., \& Fourie, C. M. T. (2009). Health care seeking behaviour of newly diagnosed HIV infected people from rural and urban communities in the North West province of South Africa. Africa Journal of Nursing and Midwifery, 11(2), 30-47.

Laditka, J. N. (2004). Physician supply, physician diversity, and outcomes of primary health care for older persons in the United States. Health \& Place, 10, 231-244.

Lauder, W. (2001). A survey of self-neglect in patients living in the community. Journal of PHC Facility Nursing, 8, 95-102.

Lloyd-Sherlock, P. (2004). Primary health care and older people in the South: a forgotten issue. The European Journal of Development Research, 16(2), 283-300.

Maree, K., Creswell, J. W., Ebersöhn, L., Eloff, R., Ferreira, R., Ivankova, N. V., et al. (2012). First steps in research. Pretoria, SA: Van Schaik.

May, J. (2003). Chronic poverty and older people in South Africa. Chronic Poverty Research Centre Working Paper No. 25. Retrieved from http://papers.ssrn.com/sol3/papers.cfm? abstract_id=1754421.

Nabalamba, A., \& Chikoko, M. (2011). Aging population challenges in Africa. African Development Bank, 1(1), 1-19.

Ntusi, N., \& Ferreira, M. (2004). South African doctors and elderly patients. Bold, 15(1), 3-13.

Orem, D. E. (2001). Nursing concepts of practice (6th ed.). St. Louis, Missouri: Mosby.
Phaswana-Mfuya, N., Petros, G., Peltzer, K., Ramlagan, S., Nkomo, N., Mohlala, G., et al. (2008). Primary health care service delivery in South Africa. International Journal of Health Care Quality Assurance, 21(6), 611-624.

SPSS. (2008). Data analysis with comprehensive statistics software. Illinois: SPSS Inc. Headquarters. Retrieved from http//www. spss.com/SPSS/.

Statistics South Africa. (2011). Midyear population estimates. Retrieved from http://www.statssa.gov.za/publications/P0302/ P03022011.pdf.

Statistics South Africa. (2012). Social profile of vulnerable groups in South Africa 2002-2011. Retrieved from http://www.statssa.gov. za/publications/Report-03-19-00/Report-03-19-002011.pdf.

The DG Murray Trust. (2012). Confluence of ideas and practice. Inclusion of the most left out. Neighbourhood Old Age Homes STTOP, 7.

Tomey, A. M., \& Alligood, M. R. (2006). Nursing theorists and their work (6th ed.). St. Louis, Missouri: Mosby.

Turok, M. (2006). South African older persons forum. Steering committee.

Turok, M. (2009). Gerontological nursing science. South African older persons forum. Retrieved from http://saopf.org.za/pressrelease/gerontological-nursing-science.

Vožehovă, S., Zikmundovă, K., Zavăzalovă, H., Zaremba, V., \& Vlasăk, J. (2003). Trends in primary health care consumption by the elderly. ACTA Medica Austriaca, 30(2), 48-50.

Watson, M. J. (2008). Community based collaboration to support the older person in the world of HIV/AIDS (Unpublished doctoral thesis). South Africa: North-West University.

World Health Organization. (2013). Aging and life course. Retrieved from http://www.who.int/ageing/events/idop_rationale/en/. 